\title{
Acknowledgements from the Editorial Office
}

Early concepts related with ecology, such as food chains, population regulation, and productivity, were first developed in the 1700s. However, modern ecology is a young science. As a branch of biology, ecology studies the interactions among organisms and their environment, including the biodiversity, distribution, biomass, populations of organisms, and cooperation and competition within and between species. Ecology has practical applications in conservation biology, wetland management, natural resource management, city planning, community health, economics, basic and applied science, and human social interaction, and this important science is closely related with our sustainable development.

Last year, we decided to launch the new journal Ecology and Sustainable Development (ESD). It is devoted to publishing original and critical review articles related to current trends on the global advancements in Ecology. The journal covers the entire range of disciplines that are related to ecology and sustainable development, and it also publishes original work that provides insight into ecological fields associated with interdisciplinary approaches such as ecological engineering.

This will be a peer reviewed, open access journal. All the manuscripts are subject to a strict review process by experts in this field, and every manuscript accepted for publication undergoes careful typesetting and proofreading. After nearly one year of preparation, the first issue of the journal is finally released, and we are proud to say that every paper of the journal has been seriously treated!

We want to express our sincere appreciation to our Editor-in-Chief, Prof. Miklas Scholz, from Lund University, and all the editorial board members! Your great effort guarantees the correct direction of the journal and the quality of every paper.

We also appreciate the efforts from all the peer reviewers. We rely upon the commitment, expertise and judgement of our reviewers to maintain the high standard of our papers. Our success is impossible without the help of the reviewers.

We are also grateful to the authors who trusted us and submitted their manuscripts to this newly created journal. We will continue to work hard and smart, and cooperate with you to create a high standard, successful journal.

Ecology and Sustainable Development (ESD) Editorial Office

Isaac Scientific Publishing 